\title{
Mene, de Sozaboy: a novel in rotten English e a protagonista de Home, Sweet Home: o viés da escrita politica e socialmente engajada de Ken Saro-Wiwa
}

\section{Mene, by Sozaboy: a novel in rotten English and the protagonist of Home, Sweet Home: the bias of the politic and socially engaged written by Ken Saro-Wiwa}

\section{Celina de Oliveira Barbosa GOMES* \\ $U E L-P R$}

\section{Ângela Lamas RODRIGUES ${ }^{* *}$ \\ $U E L-P R$}

Resumo: Ao contemplar a obra do escritor nigeriano Ken Saro-Wiwa é inevitável deparar-se com um tom fortemente engajado que prima pela denúncia da opressão das minorias do Delta do Níger, em especial a do povo Ogoni. Suas obras tratam de diferentes maneiras desta questão, enfocando, por meio de personagens-chave os problemas mais significativos e críticos, determinantes da estagnação social destas comunidades. No entanto, é em Sozaboy: a novel in rotten English e em Home, Sweet Home que a elucidação dos conflitos das minorias étnicas e das populações carentes da Nigéria será realizada. Isto porque, aqui, o autor se valerá do ponto de vista e da voz de seus protagonistas para falar por meio deles e expressar suas denúncias de um país marcado pela falência da liderança e pelas desigualdades étnicas. Este trabalho objetivou mostrar, então, como a política e a literatura se associam na escrita saro-wiwana e como esta produção é representativa de um discurso próprio do autor. Para isso, foram contemplados autores como Na'Allah (1998), North (2001), Comfort (2002), Cox (2013) e outros.

Palavras-chave: Política. Literatura. Saro-Wiwa. Escrita engajada. Povo Ogoni.

\author{
* Mestranda em \\ Estudos Literários - \\ Literatura Africana \\ de Língua Inglesa. \\ celinalua@hotmail. \\ com \\ ** Pós-doutorado \\ pelo Departamento \\ de Letras Modernas \\ da Universidade \\ de São Paulo. \\ Professora Adjunta \\ da Universidade \\ Estadual de Londrina.
}

\begin{abstract}
In contemplating the work of Nigerian writer Ken Saro-Wiwa is inevitable encounter a heavily engaged tone that press by denouncing oppression of minorities in the Niger Delta, particularly the Ogoni people. His works deal with different ways of this issue, focusing through the key-figures the most significant and critical issues, determinants of social stagnation of these communities. However, it is in Sozaboy: a novel in rotten English and Home, Sweet Home to the understanding of conflicts of ethnic minorities and poor people of Nigeria will be held. This is because, here, the author will make use of point of view and voice of its protagonists to talk through them and express their complaints in a country marked by the failure of leadership and the ethnic inequalities. This paper we
\end{abstract}


show then how politics and literature are associated in saro-wiwana writing and how this production is representative of an author's own speech. For this purpose, the authors have been contemplated as Na'Allah (1998), North (2001), Comfort (2002), Cox (2013) and others.

Keywords: Politics. Literature. Saro-Wiwa. Written engaged. Ogoni people.

\section{Introdução}

Ao comparar-se a história de vida de Ken Saro-Wiwa com sua produção literária, chega-se a uma conclusão apresentada em proposição apontada por North (2001, p.96): "Saro-Wiwa não foi morto por sua escrita, mas por sua atuação como ativista ecológico e político. Segundo o professor, seus escritos tinham relevância, pois se acomodavam convenientemente no contexto de sua produção e davam voz, cor e forma à sua luta.”

Segundo Comfort (2002, p.232), pelas diferentes produções de Ken Saro-Wiwa, ele caracterizava-se como participante na criação de uma cultura popular para a classe média urbana que rejeitava/rejeita a revalorização da cultura dita tradicional, a qual, potencialmente, poderia tornar-se dominante no futuro na literatura africana. Sua influência intelectual, segundo este autor, começava a tornar-se expressiva, não obstante a contradição que se assentava entre a recusa de uma romancização folclórica do mote nigeriano e uma enfática defesa da causa Ogoni.

O autor não se autodenominava como socialista (como se poderia dizer, de acordo com Comfort (2002, p.232), de escritores como Ngugi wa Thiong'o e Wole Soyinka), mesmo seu pensamento contendo poderosas críticas ao capital global. No entanto, sua política era transicional, pragmática e, às vezes, contraditória, pautando-se, nas esferas nacional e internacional, na defesa da causa Ogoni. Questionando-se em que tipo de nação estava vivendo, Saro-Wiwa denunciava em seus textos a perda da autodeterminação e da autonomia nigerianas, da identidade nacional e da falência da liderança governamental, que ao invés de proteger, subjugava as massas.

Em sua ação pelas minorias, propunha um reexame do perfil de país em que a Nigéria estava se convertendo e no tipo de pátria que ela desejava ser. Esta reflexão do escritor ia diretamente ao encontro da luta Ogoni. Ao sugerir uma avaliação da situação da atual Nigéria, o ativista chamava a atenção para a necessidade de reflexão sobre a exclusão do desenvolvimento e no empobrecimento desta minoria étnica (NORTH, 2001, p.98). E a ferramenta que utiliza para requerer esta preocupação coletiva é a literatura, através, entre outras produções, de dois de seus mais famosos escritos, o romance Sozaboy: a novel in rotten English e o conto Home, Sweet Home, da obra A Forest of Flowers. 


\section{Mene, de Sozaboy e a Protagonista de Home, Sweet Home: porta-vozes saro-wiwianos da insubordinação étnica}

Mene, o protagonista da narrativa antiguerra de Saro-Wiwa, é um jovem Ogoni e é por sua perspectiva - inicialmente ingênua e posteriormente desalienada pela crueldade da guerra - que se poderá perceber como o escritor revelará as atrocidades que são cometidas nas diferentes comunidades desta etnia.

A obra saro-wiwiana apresenta o modo como o conflito armado influenciou a vida de diferentes vilarejos distribuídos ao longo do Delta do Níger. Vai mostrar como os efeitos da guerra adulteraram não só os aspectos físicos, mas principalmente identitários de muitos dos indivíduos Ogoni, a exemplo do que ocorrera com seu protagonista, o chamado Sozaboy. O confronto na obra não é localizado, tampouco são identificados seus executores e isto acontece por dois motivos principais: tanto para dar o tom de universalidade do prélio, atestando os diferentes embates e os diferentes inimigos contra os quais os Ogoni deveriam lutar; quanto para sugerir que os oponentes deste povo poderiam ser o secessionistas da Biafra e mesmo o Estado Federal Nigeriano, impulsionador das maiorias étnicas. Evidências de que este perfil de inimigo é confuso para Sozaboy podem ser consideradas no seguinte excerto:

[...] E estas pessoas que eles estão chamando de 'inimigo' o tempo todo. Como o inimigo pode me dar comida, injetar-me remédio até que eu fique bem, dar-me automóvel para eu dirigir, mesmo sem eu ter habilitação, dar-me um bom uniforme e um rifle fantástico. Então, eu sou um tolo por todo este tempo em que estou querendo para matar este inimigo! ${ }^{1}$ (SAROWIWA, 1985, p.126) [tradução nossa].

A incompreensão da natureza real do conflito, muitas vezes demonstrada em passagens como: "Então, por que estamos nós estamos lutando?”2 (SARO-WIWA, 1985, p.90) [tradução nossa], sugere o teor neocolonial do enfrentamento e das relações de poder estabelecidas pela e com a Nigéria. Esta ação neocolonial visa, como supracitado, não só dizimar as instâncias naturais de Dukana, cenário principal da narrativa, mas descaracterizar a essência de suas populações, seduzindo-as com as possibilidades oferecidas pela aparente modernidade e evolução supostamente advindas com a guerra. Quando Mene vê a possibilidade de tornar-se um soza, ou seja, um soldado, contempla uma alternativa de ascensão social e de melhoria de vida para si e para os seus. Mas além de acreditar em uma mudança em seu status social, tem a certeza de que abrindo mão de sua atual identidade para tornar-se um "sozaboy" vai inserir-se no universo daqueles que mandam, que ditam as regras e que, de alguma forma, oprimem.

Por mais que não deseje proceder como estes sujeitos, no que se refere à subjugação de seus pares, Mene almeja o mesmo respeito e a mesma
1 " [...] And na these people they are calling 'enemy' all the time. How enemy will give me chop, chook me medicine till I well, give me motor to drive without I no get licence, give me fine fine uniform and then very fantastic rifle. So I am a fool all this time that I am wanting to kill this enemy!". (SAROWIWA, 1985, p.126).

2 "Then why are we fighting then?” (SARO-WIWA, 1985, p.90). 
deferência que eles recebem. Este tratamento especial é dado em função do título e da farda que vestem. No entanto, o que o jovem e muitos outros como ele não percebem é que ao esvaziar-se de suas configurações comunitárias, ao não desejar mais ser chamado por seu nome e sim por Sozaboy, adere e aceita um rótulo que justamente rouba-lhe a identidade. Este rótulo despersonifica-lhe e o configura como só mais um entre tantos outros soldados. Isto é profundamente trágico quando se considera a colocação de Seiyifa Koroye citada por North (2001, p. 105). Segundo Koroye, "Mene” significa "rei" em Khana e ao abrir mão de seu nome, o protagonista também abdica de um poder real, legitimado por sua identidade Ogoni e, por conseguinte, nigeriana, de empreender as mudanças necessárias para defender sua terra e a soberania de sua gente. Ao preterir sua designação cultural, Mene renuncia ao prestígio em sua própria sociedade pela falsa promessa de poder em um lugar qualquer, recebendo em troca, na verdade, somente a subserviência e a humilhação.

Ao finalizar sua narrativa, Mene não é nem mais rei, nem mais soldado. É agora um fantasma, um homem que representa a morte em uma comunidade que está totalmente afundada na miséria, na fome e na pestilência, consequências do conflito armado. Em um lugar em que poderia ser o agente da transformação e da evolução, o jovem agora é visto como um mau presságio, uma influência ruim que só traz desgraças. Isto porque sua partida coincidiu com a guerra, com os roubos e com as epidemias que assolaram a cidade de Dukana e as de seu entorno. E, além disso, ao regressar para casa em busca de sua família, Mene era encarado pelas pessoas como uma espécie de morto-vivo, uma alma sem descanso que, enfurecida pela perda da esposa e da mãe, puniria a comunidade com tragédias. Este temor se tornou mais forte, pois logo após o retorno de Sozaboy, diferentes casos de varíola começaram a manifestar-se na cidade e muitos de seus habitantes morreram (NORTH, 2001, p.105).

A aniquilação da identidade de Mene é sintomática da própria situação dos Ogoni. Mesmo isolado, representa as minorias étnicas que perderam sua especificidade, sua representação, como ocorreu com esta etnia no contexto neocolonial. Os Ogoni tiveram sua representatividade dissolvida no conflito entre a Nigéria e a Biafra. A fome a pestilência que oprimiu estas populações iniciaram-se quando sua representação e soberania foram subjugadas pelo poder colonial. Esta é uma situação chocante quando são consideradas as especificidades deste povo. A etnia contava com cerca de quinhentos mil membros, distribuídos em seis reinos. Nestas localidades, entre outras manifestações linguísticas, quatro línguas eram faladas majoritariamente, dentre elas o Khana e o inglês, como visto no capítulo anterior (COMFORT, 2002, p.232).

Quanto à indefinição do inimigo, não importava o lado para o qual Sozaboy estava lutando; um funcionava como espelho do outro na 
degradação destes habitantes. E este espelho do terror refletia ainda os conflitos e desmandos da era colonial, configurando-se agora em uma irônica representação do neocolonialismo.

A narrativa antiguerra de Ken Saro-Wiwa sugere, portanto, um modelo de comunidade sintética, coesa, a exemplo de outras comunidades afetadas pela guerra. E neste modelo, aparentes antagonismos se apresentam, como o do desejo de uma etnia Ogoni independente e, ao mesmo tempo, da necessidade da integração destas populações a outros grupos como forma de encontrar resistência conta o poder estatal subserviente ao mando estrangeiro e mesmo contra a opressão dos grupos maiores.

No conto Home, Sweet Home, apresenta-se o narrador feminino de Ken Saro-Wiwa, que é expressivamente marcado pelo o "empoderamento" de seu discurso e a delação das mazelas políticas e sociais de sua comunidade. Esta é uma forma peculiar que o autor utiliza, inclusive, para descontruir certos paradigmas de gênero que tolhem a fala à mulher, inclusive, em sua comunidade. Estes mesmos modelos de subordinação feminina serão, a propósito, criticados por Saro-Wiwa pela ilustração que o escritor faz da figura de Sira, a melhor amiga da protagonista. Sira é uma moça de idade similar, mas que permaneceu em Dukana, ambiente também do Sozaboy, é recebeu toda carga de arcaísmos culturais e sociais daquela comunidade. Teve vários filhos, por ordem dos pais que acreditavam na função reprodutora da mulher e na continuação da descendência e, por isso, não pode concluir os estudos, como se vê no excerto:

Ela [Sira] não tinha sido capaz de completar a escola elementar, embora fosse uma garota brilhante. Ela disse que a mãe não pode pagar as taxas. Mas era apenas uma desculpa. Seus pais queriam que ela tivesse filhos, procriasse para que a família não terminasse. $E$ ela tinha que lhes obedecer. Ela não se casou e seus quatro filhos eram de quatro homens diferentes. Eu suspeito que sua quinta gravidez era de um quinto homem. (SARO-WIWA, 1986, p.9). [tradução e grifo nossos].

A protagonista de Home, Sweet Home irá receber influxos acadêmicos ocidentais, em uma conjuntura pós-colonial, retornando posteriormente à sua terra e reagindo frente à postura dos sujeitos femininos, seus pares. Sua reação, no entanto, não será de rechaço, mas de acolhimento, de pacto, de desejo de integração e luta pela evolução daqueles habitantes, membros também da etnia Ogoni, que foram subjugados por aquela mesma força ocidental e pelas maiorias étnicas.

Home, Sweet Home tratará da conscientização do isolamento em que vivem em Dukana e dos privilégios da “iluminação”, advindos de estudos e viagens. Como ocorre com o protagonista de Sozaboy a personagem desta narrativa também se sentirá impelida a sair de um processo de entorpecimento natural à sua comunidade. E esta libertação só será possível porque ela "se retirará” propriamente desta atmosfera. 
Segundo Okereke (2000, p. 123) citado por Na’Allah (1998), esta visada feminina empreendida por Ken Saro-Wiwa na concepção, especialmente, das primeiras histórias de A Forest of Flowers ("Home, Sweet Home”, "Love Song of a Housewife”, “The Divorce”, "Night Ride” e “A Caring Men” (na segunda parte)), propõe uma intersecção com a construção do gênero masculino. Sugere uma observação de como ele se relaciona com o feminino na determinação de relações sociais de poder, inclusive, dentro do próprio casamento. Esta apropriação de posturas sentimentais de ambos os gêneros, na narração de uma experiência feminina, reflete o ponto de vista de Bakhtin sobre a consciência como um terreno de diferentes caminhos para apreender o mundo ((CLARK e HOLQUIST, 1984) citado por NA'ALLAH (1998)).

A consciência feminina nas histórias saro-wiwianas é imbuída de sabedoria e de uma sutil capacidade de ironia, a qual emprega em seus comentários sobre a população e sobre o governo. O narrador não é nomeado, mas é informado no texto, demonstrando pensamentos analíticos. Esta posição tomada por uma consciência de mulher e de jovem busca orientar e nutrir as jovens mentes como a dela em Dukana, mobilizando-as, potencialmente, para a mudança. Dando voz a uma consciência feminina para narrar o conto de abertura de sua coletânea, esta cravejada de inflexões políticas, Ken Saro-Wiwa empodera a mulher para articular-se em um espaço definido por um código tradicional masculino (NA’ALLAH (1998).

O narrador feminino coletiviza, em sua história, tanto a narrativa da população de Dukana (mulheres e homens), quanto a narrativa de gênero de seu sexo. Ambos os enfoques se interseccionam, expressando a situação comum de opressão e dominação. Acerca da população, a abordagem se dá pela depravação de algumas pessoas e pelo sofrimento de outras pela atuação dos produtores de petróleo. Há uma identificação - solidária - da consciência narrativa com o povo, este submetido, por sua ignorância e pobreza, pelas forças predadoras de exploração vindas de fora.

A inominada personagem sabe de sua responsabilidade como esclarecedora das mentes entre a população explorada. Também é consciente da dupla deficiência em que seu povo vive: a que se refere às configurações de gênero e a que se atrela à falta de informação, deixando-os suscetíveis (e a sua terra) à ação dos predadores econômicos desejosos dela (NA'ALLAH (1998)). Esta assertiva acerca do gênero vai ao encontro ao que Bonnici (2009, p.266) atesta ao dizer que "se o homem foi colonizado, a mulher, nas sociedades pós-coloniais, foi duplamente colonizada.” Tomando a posição de uma consciência feminina, Saro-Wiwa intertextualiza a narrativa com a impotência da minoria da população Ogoni, abusada na captação de suas reservas ambientais e de óleo. O texto remete à sua luta pela sobrevivência contra o peso monstruoso do capital estrangeiro, tal qual o faz a personagem, na tentativa de revelação das capacidades e tentativas de resistência de seu gênero, entre outras lutas. 
A construção da perspectiva feminina sobre normas culturais que privilegiam o masculino demonstra uma tentativa de Ken Saro-Wiwa em engajar a sociedade em um discurso sobre a mudança. Esta mensagem estrutura-se em uma base humanitária e harmônica, buscando promover melhor o relacionamento entre mulheres e homens, no intuito de suscitar, de fato, uma transformação (OKEREKE, 2000, p. 134 citado por NA'ALLAH(1998)).

\section{A opressão dos Ogoni pelas maiorias étnicas}

Quando se fala de uma resistência à subjugação por etnias dominantes, se procede a uma discussão que se justifica pela exacerbada tensão entre diferenças étnicas que a independência nigeriana provocou no ano de 1960. Segundo Saro-Wiwa (1992, p.25), grande parte da destruição das populações Ogoni e de outros coletivos menores se deu com a estruturação política da nação em três grandes regiões dominadas pelos grupos majoritários Haussá e Fula, Iorubá e Igbo. Como possuíam maior representatividade, estes grupos determinavam as regras de exploração de territórios, apoiados pelo governo e se valiam, segundo Saro-Wiwa (1992, p.26), da fragilidade das minorias para estabelecerem suas determinações, já que entre elas havia divergência de línguas, culturas e objetivos. Como forma de defender seus direitos e assegurar sua autonomia, cada um destes grupos menores se posicionou contra a força das grandes etnias, buscando obter o poder estatal. No tocante aos Ogoni, estes eram favoráveis à criação do Estado de Rivers e da designação de um representante desta congregação para o poder. No entanto e como era de se esperar em função das tímidas possiblidades das minorias em relação aos seus oponentes, a disputa pelo mando ficou entre as três maiores etnias. Após violentas disputas entre elas, das quais resultaram vários assassinatos de líderes e demais membros da etnia Igbo, esta acusada de etnocentrismo por ter o maior número de representantes no poder, a organização da nação em federação se dissipou e o caos tomou conta da situação. Por outro lado, as minorias étnicas sugeriram a continuidade da existência do país e recomendaram a reestruturação política da nação em estados. O requerimento dos pequenos coletivos foi aceito, mas os Igbo, sob a liderança do Coronel Odumegwu Ojukwu não acolheram a proposta e deflagraram uma rebelião separando-se da federação. Declararam então a república da Biafra, no leste da Nigéria. Como se poderia supor, os grupos localizados nesta região, dentre eles, as comunidades Ogoni, ficariam na linha de fogo entre as forças federais nigerianas e estes chamados rebeldes da Biafra. Além disso, como forma de punir os habitantes do Delta do Níger, região em questão, o Coronel Odumegwu Ojukwu passou a oprimir significativamente estes indivíduos. Suas populações eram tidas como escravas e servas de uma força que as coibia pelo horror e pela desumanidade de um líder intransigente e egoísta (SARO-WIWA, 1992, p.27). 
Ainda segundo Saro-Wiwa (1992, p.28), ao final de seu propósito de criação de uma nova república, o Coronel Ojukwu já contava com cerca de vinte unidades provinciais e outras divisões administrativas, mas este não era seu objetivo primeiro. O militar almejava o controle de exploração do petróleo no Delta, mas precisamente nas terras Ogoni. Tinha a certeza de que se detivesse o poder sobre os recursos advindos da captação do mineral, poderia ampliar suas fronteiras e, principalmente, sua força. Mas esta era a mesma meta do atual mandatário do Estado Federal Nigeriano. E foi por isso que ambos os lados travaram uma guerra pelos domínios do território, o que vitimou sobremaneira, de forma cruel e desumana, as populações desta localidade, dentre elas os Ogoni, os habitantes de Dukana, por exemplo. Para que o objetivo de qualquer um dos combatentes se cumprisse, estas minorias careciam ser exterminadas, por configuravam um empecilho, sobretudo, quando ofereciam resistência. Foi por isso que estratégias de cooptação de suas lideranças, como visto pela corrupção do Chief Birabee, por exemplo, e do apagamento de sua identidade cultural, como protagonizado por Mene, tornaram-se alternativas para ruir internamente o que as bombas e balas não conseguiam destruir.

Neste intento genocida, cerca de trinta mil membros Ogoni morreram na guerra. E, para o autor de Sozaboy e de Home, Sweet Home, vinte anos após a barbárie, a Nigéria parece não relegar a importância necessária à etnia, como se esta não fizesse parte da miscelânea cultural do país.

Saro-Wiwa (1992, p. 42) ainda sugere que a dizimação dos Ogoni teria sido providencial, já que suas terras ficariam assim livres para a exploração (SARO-WIWA, 1992, p.43). O desabafo de Saro-Wiwa encontra respaldo nas conclusões de Cox (2013, p.38) [tradução nossa]. O teórico diz que: "[...] Petróleo e gás vão parar de mão em mão com estados corruptos, forças policiais assassinas, juízes que fazem o que elas diziam para fazer e uma mídia comprada”’ . E é nesta perspectiva que ele vai produzir o seu Sozaboy, mecanismo de crítica à guerra que exterminou grande parte das populações do Delta do Níger, e Home, Sweet Home, espelho da pobreza e estagnação nigeriana. Como obras literárias, os escritos poderiam/ poderão carregar, por tempo indeterminado, uma mensagem de transformação - esta que se faz urgente pela desalienação - de sua situação frente à força dos grupos de maior representatividade e mesmo do Estado Federal da Nigéria, este, segundo ele corrupto. Para Cox (2013, p.38), por exemplo, ao permanecerem em suas próprias terras e lutando por sua existência futura, as comunidades mostrariam extraordinária coragem em face desta intimidação, além de grande generosidade - leia-se companheirismo através de batalhas similares em qualquer lugar.

Esta seria uma visão poética de como estes povos deveriam viver e uma clara perspectiva das realidades, não apenas de poder, mas de períodos de tempo no qual se deveria pensar em querer ver as futuras gerações,
3 “Oil and gas go hand in hand with corrupt states, thuggish police forces, judges who do what they are told and a bought media." (COX, 2013, p.38). 
netos e não simplesmente contas bancárias. Em outras palavras, o teórico corrobora a chamada para o despertar e para a ação perpetrada por SaroWiwa, de maneira que todos possam, no futuro, contemplar uma vida mais digna e salutar; adverte para que não se deixem seduzir pelo aparelho neocolonial e nem tampouco se deixem abater pela ação bélica em suas comunidades, sugerindo moldes similares ao de Sozaboy e de Home, Sweet Home no que tange à necessidade de se ter uma sociedade coesa e coerente com seus próprios princípios (COX, 2013, p.38).

Segundo Garuba (1998, p.230):

Em seus vários discursos, escritos e outras atividades, Ken Saro-Wiwa procurou desenhar discursivamente a atenção para as realidades do lento genocídio do povo Ogoni e a degradação de seu ambiente, porque ele reconheceu que o fato da inabilidade das populações Ogoni para representarse a si mesmas tem feito sua situação mais trágica e suas circunstâncias mais desanimadoras. A missão dele, portanto, era dar voz aos silenciados, à minoria marginalizada que não estava sendo apenas fisicamente dizimada como pessoas, mas que tinha sido também, representativamente, apagada da consciência nacional e internacional. ${ }^{4}$ (GARUBA, 1998, p.230) [tradução nossa].

Para tanto, é tomado o ponto de vista do jovem Mene e da Protagonista inominada de Home, Sweet Home, que funcionarão como representantes de todos os Ogoni. Eles simbolizarão aqui este processo de utopia (e porta-voz do próprio Saro-Wiwa), consequente desalienação e desejo de libertação do opressor [da guerra, da ignorância e da subordinação, no caso] enquanto membro das minorias étnicas.

\section{Considerações finais}

Como já demonstrou em diferentes trabalhos e pela vida de lutas e intensa produção bibliográfica engajada, porém, não menos literária, a política e a literatura sempre andaram juntas nos escritos de Ken Saro-Wiwa. E a temática de seus textos não era outra senão a luta pela insubordinação do povo Ogoni, das minorias étnicas e a manutenção da integridade ambiental. Foram estas as questões que o sentenciaram a morte por enforcamento, mas que, apesar disso, deixaram marcado seu nome na história da defesa ambiental e na literatura africana de expressão inglesa, de modo geral.

Em Sozaboy: a novel in rotten English e em Home, Sweet Home Ken Saro-Wiwa utiliza a voz e olhar de seus protagonistas para evidenciar as questões de degradação ambiental, cultural, social e a falência de liderança que assola a cidade de Dukana, mas que é sintomática da própria Nigéria. Utiliza sua escrita literária como metáfora do conflito armado e da intensa estagnação aos quais as comunidades étnicas minoritárias
4 "In his various speeches, writings and others activities, Ken Saro-Wiwa had sought to draw discursive attention to the realities of the also genocide of the Ogoni people and the degradation of their environment because he recognized the fact that the inability of the Ogoni people to represent themselves had made their situation more tragic and their circumstances more despondent. His mission, therefore, was to give voice to a silenced, marginalized minority who were not only being physically decimated as a people but who had also been representationally erased from national and international consciousness. (GARUBA, 1998, p.230). 
foram subjugadas, a fim de delatar a inoperância do poder público em representá-las e defendê-las da ação exploratória do poderio internacional e da iniciativa genocida dos grupos étnicos maiores.

Mene e a protagonista de Home, Sweet Home são pares em um processo de desalienação, apesar deste “desentorpecimento” ter se dado por caminhos diferentes: ele pelas agruras da guerra, e ela pelos estudos e a saída de Dukana. Esta correspondência entre ambos reflete o perfil do próprio Saro-Wiwa, de sua atuação proselitista em favor do povo Ogoni e de sua configuração como intelectual da ação que desvencilhou-se das utopias neoliberais para enxergar as necessidades reais de sua comunidade. Portanto, tanto Sozaboy: a novel in rotten English quanto Home, Sweet são legítimos exemplares de uma escrita política e socialmente engajada; ação que deu conta de levar a diferentes partes do mundo, haja vista este e outros trabalhos, a denúncia de subjugação do povo Ogoni e o grito de um ideal de luta pautado na transformação social.

\section{Referências}

BONNICI, T. Teoria e crítica pós-colonialistas. In: ; ZOLIN, L. O. Teoria Literária: uma abordagem e tendências contemporâneas. 2 Ed. Maringá: Eduem, 2005, p.257-285.

COMFORT, S. Struggle in Ogoniland: Ken Saro-Wiwa and the Cultural Politics of Environmental Justice. In: ADAMSON, J.; EVANS, M. M.; STEIN, R. The environmental justice reader: politics, poetics and pedagogy. Arizona - USA: The University of Arizona Press, 2002, p.229246.

COX, L. Ken Saro-Wiwa in Political Context: Social Movements in the Niger Delta. In: CORLEY, Í.; FALLON, H.; COX, L. Silence would be treason: last writings of Ken Saro-Wiwa. Dakar: Codesria/Daraja, 2013, p. 31-38.

GARUBA, H. Ken Saro-Wiwa's Sozaboy and The Logic of Minority Discourse. In: OKOME, O. Before I am hanged - Ken Saro-Wiwa: Literature, Politics and Dissent. Trenton - NJ/Asmara - Eritrea, 2000, p. 25-36.

NA’ALLAH, A. R. Ken Saro-Wiwa: A Bio-bibliography. In:

Ogoni's Agonies: Ken Saro-Wiwa and the Crisis in Nigeria. Trenton, NJ: African World Press, 1998, p.363-377.

NORTH, M. Ken Saro-Wiwa's Sozaboy: The Politics of the "Rotten English”. Public Culture. England, v. 13, n. 1, apr/aug. 2001. Disponível em: <www.deepdyve.com/lp/duke-university-press/ken-saro-wiwa-ssozaboy-the-politics-of-rotten-englsih-bQON4YxCVR/10>. Acesso em: 15 jun.2014. 
SARO-WIWA, K. Genocide in Nigeria: The Ogoni Tragedy. Port Harcourt - NJ: Saros International Publishers, 1992.

Home, Sweet Home. In: A Forest of Flowers. Port Harcourt Nigeria: Longman African Writers, 1986.

Sozaboy: a novel in rotten English. Port Harcourt - NJ: Saros International Publishers, 1985.

Enviado: 30/11/2014

Aprovado: 02/03/2015 